\title{
Debulking of pituitary adenomas improves hormonal control of acromegaly by somatostatin analogues
}

\author{
John Wass \\ Department of Endocrinology, University of Oxford, Churchill Hospital, Oxford OX3 7LJ, UK
}

(Correspondence should be addressed to J A H Wass; Email: John.Wass@noc.anglox.nhs.uk)

A large number of issues remain regarding the optimal treatment of patients with acromegaly. One debate that is current is whether surgery or primary medical treatment is indicated in patients with tumours, usually with extrasellar extensions, that are unlikely to be cured by surgical means. Will debulking surgery help the subsequent response to medical therapy? The recent article by Petrossians et al. (1) goes someway to answering this important question.

We know that in the best surgical hands microadenomas have a high cure rate of around $90 \%$ in acromegaly (2). These patients often have lowish growth hormone (GH) levels. Indeed any treatment - be it surgery, medical therapy or radiotherapy - is most successful in patients with low GH levels. However, at least $60 \%$ of patients have macroadenomas when they present with acromegaly. These patients often have higher GH levels and there may even be an extension of the lateral side of the pituitary tumour into the cavernous sinus, making surgery much more difficult. In these circumstances success by surgical means, usually using the transphenoidal route, is very much less frequent, around $50 \%$ (3). Suprasellar extensions are more likely to be cured than lateral extensions and if transfrontal craniotomy is necessary we know that that there is virtually no hope of a cure by surgical means (4). Unfortunately other modalities of treatment for acromegaly in the circumstances of a large tumour with extrasellar extension and high growth hormone levels similarly are less successful. Thus we know that external beam radiotherapy given to patients with high growth hormone levels takes significantly longer to be effective and normalises growth hormone levels at 10 years post-treatment in between 50 and $60 \%$ and insulin growth factor-I (IGF-I) in roughly the same proportion (5). Likewise the responses to somatostatin analogues depend on the pre-treatment growth hormone (6). For example, if the pre-treatment $\mathrm{GH}$ level is around $5 \mathrm{ng} / \mathrm{ml}$ some $60 \%$ of patients will respond. However, if it is much higher the response rates are much lower. Thus a successful outcome is more likely in response to surgery, medical therapy with somatostatin analogues and radiotherapy if the $\mathrm{GH}$ level is lower.

Does lowering the $\mathrm{GH}$ by debulking non-curative surgery improve the outcome of medical therapy?
A number of series report the use of primary medical therapy for the treatment of acromegaly (7). The rationale is that when responses of patients to somatostatin analogues are assessed in two groups, one given primary therapy and the second given therapy with somatostatin analogues after unsuccessful surgery, the two groups have roughly similar post-treatment GH and IGF-I outcomes. Primary therapy seems, in the studies that have been published thus far, to be equally as effective as secondary therapy (8). Certainly primary therapy can be suggested in patients who are either unfit or too elderly to undergo transphenoidal surgery.

The above studies however have not included a within-patient comparison of debulking pituitary surgery to assess the rate of biochemical normalisation using somatostatin analogue after unsuccessful surgery; in particular to see whether debulking surgery improves biochemical normalisation of GH and IGF-I in individuals in whom the responses to these analogues has been assessed pre-operatively. The rationale here, as above, is that one might expect a better outcome in response to somatostatin analogues after an operation that has been successful at lowering GH levels (even if not to normal levels) by removing some or most of the pituitary tumour mass.

The first study that has assessed this (Petrossians et al. (9)) suggests that indeed debulking surgery, even if unsuccessful, improves the post-surgical outcome of somatostatin analogues given post-operatively when compared with pre-operative response in the same patients. Thus pre-operatively, after medical therapy with various somatostatin analogues $\mathrm{GH}$ normalisation was achieved in $29 \%$ of patients. After debulking surgery and further post-operative treatment with somatostatin analogues, this figure rose to $54 \%$. The figures for IGF-I were more impressive, rising from $46 \%$ normalisation with pre-operative medical therapy up to $78 \%$ normalisation with post-operative medical therapy.

Nothing in life is perfect and this study does not quite achieve perfection in a number of ways. For the most part the patients were treated with subcutaneous analogues. We know that these are less effective than the long-acting preparations, lanreotide autogel and octreotide LAR (9). Lanreotide is not as effective as 
octreotide in reducing IGF-I levels to normal but it is probable that octreotide LAR and lanreotide autogel are equally efficacious $(10,11)$. Furthermore, because this study was retrospective, three patients out of 24 only had pre-operative treatment for a month and thus it is difficult to assess whether the maximum benefit in terms of GH and IGF-I reduction was achieved in all patients. We do not know whether there was a reduction in tumour volume or whether pre-surgical treatment affected the surgical outcome in this study. In a perfect study the patients would be given the same drug and preparation pre- and post-operatively and in six of the 24 patients in this study this did not occur. Nevertheless this is an important study which points the way to the future beneficial effects of debulking surgery in acromegaly.

We now need a prospective study looking at the use of long-acting analogues of somatostatin given for a finite period to achieve maximal GH and IGF-I suppression pre-operatively. In those that are unsuccessfully treated surgically, post-operatively there should be reexposure to the somatostatin analogue (using the same drug again) to achieve maximal GH and IGF-I suppression. Besides assessing whether debulking surgery improves the outcome when using somatostatin analogues, such a study should also assess the effect of pre-operative somatostatin analogue therapy on surgical outcomes. Such studies are underway and should be available shortly.

\section{References}

1 Petrossians P, Borges-Martins L, Espinoza C, Daly A, Betea D, Valdes-Socin H, Stevenaert A, Chanson P \& Beckers A. Gross total resection or debulking of pituitary adenomas improves hormonal control of acromegaly by somatostatin analogs. European Journal of Endocrinology 2005152 61-66.
2 Wass JAH, Turner HE \& Adams CBT. The importance of locating a good pituitary surgeon. Pituitary 19992 51-54.

3 Ahmed S, Elsheikh M, Page RCL, Adams CBT \& Wass JAH. Outcome of transphenoidal surgery for acromegaly and its relationship to surgical experience. Clinical Endocrinology $1999 \mathbf{5 0}$ $561-567$.

4 Fahlbusch R, Buchfelder M, Kreutzer EJ \& Nomikos P. Surgical management of acromegaly. In Handbook of Acromegaly, Ed J Wass. Bristol: BioScientifica, 2001.

5 Ciccarelli E, Corsello SM, Plowman PN, Jones AE, Touzel E, Rees LH, Besser GM \& Wass JAC. Long-term effects of radiotherapy for acromegaly on circulating prolactin. Acta Endocrinologica $1989121827-832$.

6 Bevan JS, Atkin SL, Atkinson AB, Bouloux P-M, Hanna F, Harris PE, James RA, McConnell M, Roberts GA, Scanlon MF, Stewart PM, Teasdale E, Turner HE, Wass JAH \& Wardlaw JM. Primary medical therapy for acromegaly: an open prospective, multicentre study of subcutaneous and intramuscular slow-release Octreotide on GH, IGF-1 and tumour size. Journal of Clinical Endocrinology and Metabolism 200287 4554-4563.

7 Ayuk J, Stewart SE, Stewart PM, Sheppard MC \& European Sandostatin LAR Group. Efficacy of Sandostatin LAR (long-acting somatostatin analogue) is similar in patients with untreated acromegaly and in those previously treated with surgery and/or radiotherapy. Clinical Endocrinology $200460375-381$.

8 Freda PU \& Wardlaw SL. Primary medical therapy for acromegaly. Journal of Clinical Endocrinology and Metabolism $1998 \mathbf{8 3}$ 3031-3033.

9 Ashwell SG, Bevan JS, Edwards OM, Harris MM, Holmes C, Middleton MA \& James RA. The efficacy and safety of lanreotide Autogel in patients with acromegaly previously treated with octrestide LAR. European Journal of Endocrinology 2004150 $473-480$.

10 Turner HE, Vadivale A, Keenan J \& Wass JAH. A comparison of lanreotide and octreotide LAR for treatment of acromegaly. Clinical Endocrinology 199951 275-280.

11 Ashwell SG, Bevan JS, Edwards OM, Harris MM, Holmes C, Middleton MA \& James RA. The efficacy and safety of lanreotide autogel in patients with acromegaly previously treated with octreotide LAR. European Journal of Endocrinology 2004150 $473-480$.

Received 24 January 2005

Accepted 25 January 2005 